\title{
Translation of Ren and Li in Lunyu
}

\author{
Qianqian Wei ${ }^{1}$ \\ ${ }^{1}$ Foreign Languages Department, Binzhou University, Binzhou, China \\ Correspondence: Qianqian Wei, Foreign Languages Department, Binzhou University, Binzhou, China. E-mail: \\ qianqianwei1231@163.com
}

Received: January 2, 2016 Accepted: January 22, 2016 Online Published: January 31, 2016

doi:10.5539/ijel.v6n1p195

URL: http://dx.doi.org/10.5539/ijel.v6n1p195

This study was supported by Shandong Provincial Key Project of Art and Science (No. 1506368), Scientific Research Fund of Binzhou University (No. BZXYRW1408) and Serving Region Project of Binzhou University (No. BZXYFB20150908).

\begin{abstract}
Lunyu (《论语》), a record of Confucius' sayings and deeds compiled by his disciples, had great influence not only on the Chinese but also on the whole world. It was translated into many languages, among which there are more than 50 English versions. In Lunyu, Confucius employed a good number of terms to express his ideas on what good ethics and politics were, such as ren (“仁”) and $l i$ (“礼”). Due to cultural differences, it is a great challenge for translators to find English equivalents of these culture-specific items. The paper will discuss the translation of two main concepts in Lunyu-ren and $l i$ through the comparison of five English versions and try to find out the proper method to translate the Chinese culture-specific items in the book.
\end{abstract}

Keywords: ren, li, Lunyu, translation, culture-specific items

\section{Introduction}

Lunyu, known as the main text of Confucianism, is the "Bible of China", and also one of the world's classic writings. It expresses Confucius' ideas of politics, education, etc. The core of the book is ren, which Confucius thought was loving people or having loyalty and consideration. To achieve it one had to use $l i$ as a norm because "to subdue one's self and return to propriety" (Legge, 2009) is ren.

For more than two thousand years, Lunyu and Confucianism were regarded as the foundation of Chinese social-cultural life. It not only cultivates individual's morality but also tells people how to run a country. Sometimes even a word or two can benefit a person for a lifetime.

Its influence has extended abroad and Confucianism has held a leading position in the East Asian cultural circles. It might be said that East Asian civilization would not come into being without Confucianism. What is more, its influence on the whole world is apparent since Confucius is considered as one of the greatest thinkers who have changed the world. Thus, it is of great significance to study the translation of Lunyu.

\section{Literature Review}

\subsection{Translation History of Lunyu}

The circulation of Lunyu in the whole world follows such a process - from the near to the distant, and first in East Asia and then in Europe and America. By the end of the $16^{\text {th }}$ century the translation of Lunyu into Western languages had begun.

Matteo Ricci (1552-1610), an early Italian missioner, had translated The Four Books from Chinese into a western language and sent them to his homeland. When his countrymen read them, they felt enjoyable; they came to know that the Chinese classics might lead people to the true origin. The so-called Western language refers to Latin. Matteo Ricci started with the translation of The Four Books in 1591, the nineteenth year of Wan Li Reign of the Ming, and he finished his translation in 1594. Unfortunately his translation was scattered and lost before publication in the first years of the Qing dynasty.

Almost a century later, Prosper Intercetta (1625-1696), an Italian Jesuit and Ignatius da Casta (1599-1666), a Portugese Jesuit, jointly translated Lunyu into Latin. Philippus Couplet (1624-1692), a Belgian Jesuit, published 
their translation in Paris in 1687. This is the first publication of Lunyu in Europe. The abridged French and English versions were separately published in France and England in 1688 and 1691. So the ordinary people might come into contact with the Confucian thought, and this aroused a praise of Confucius in the whole Western Europe.

Towards the end of the $18^{\text {th }}$ century or at the beginning of the $19^{\text {th }}$ century, The Four Books, including Lunyu, spread to America, and there were translations of English, French, Latin and other languages. In 1809, J. Marshman (1768-1837), an English missioner, published his translation of Lunyu that includes the first ten chapters. This is the first version where Chinese was directly rendered into English. In the recent two centuries, there are some other people who translated Lunyu into English. For example, there are David Collie, an English missioner, James Legge, Sir T. F. Wade, William Jennings and Gu Hongming. James Legge (1815-1897) is a Scottish missionary. In 1861 his translation of Chinese classics including Lunyu was published in Hong Kong. Dissatisfied with Legge's version, Gu Hongming published The Discourses and Sayings of Confucius in 1898. He translated Lunyu with the aim of transmitting Confucian values to the whole world. He is the first Chinese who put Lunyu into English and before him it was all translated by westerners.

In the first half of the $20^{\text {th }}$ century, many scholars, such as Lionel Giles, Leonard A. Lyall, William E. Soothill, Arthur Waley, \& Lin Yutang, translated Lunyu into English. Fascinated by ancient Chinese civilization, apart from Lunyu, Arthur Waley (1889-1996) translated seven or eight books of Chinese culture.

And since then, with China's opening-up, Confucianism is popular in the world and more than 40 English versions appeared with this trend. Pan Fuen \& Wen Shaoxia issued their version in 1993 and Lin Wusun absorbed the latest research materials and published his "new translation" in 2010. And some translators published more than one version, such as, D. C. Lau, \& Ding Wangdao. D. C. Lau, a professor in Hong Kong Chinese University, has already translated seven books including Lunyu. Until now, the English translation of Lunyu has experienced more than two centuries and there are more than 50 English versions.

\subsection{Translation Studies of Lunyu}

\subsubsection{Translation Studies Abroad of Lunyu}

There is a long history in translation studies abroad of Lunyu and it is mainly by translators and sinologists, such as Matteo Ricci, Joshua Marshman, David Collie, James Legge, Ezra Pound, \& Edward Slingerland, who were intoxicated by Chinese culture. They commented on the previous versions in the preface or appendix and illustrated why they retranslated Lunyu, which is an important part of translation studies of Lunyu. For example, Roger T. Ames \& Henry Rosement pointed in their version that the method of using western philosophical and religious words to replace the key words in Confucianism could not express the philosophy specific to China (Ames \& Rosemont, 1998). Moreover, there are book reviews in some journals of sinology and philosophy, such as, Chinese Literature: Essays, Articles, Reviews, The Journal of Asian Studies and Philosophy East and West. And in recent years, the book reviews involve more aspects and the analyses are more elaborate.

The person who analyzed translations of Lunyu most is David Schaberg, whose comments involved many perspectives of language, philosophy, history and style. Cheuk-Woon Tamm (1953) had a brief comment on all English versions before WWII. And Alice W. Cheang (2000), Stephen W. Durrant (1981), John Henderson (1999), Edward Slingerland (2000), Lauren Pfister (1990, 2004) and Norman J. Girardot (2002) all expressed their opinions on different versions.

\subsubsection{Translation Studies of Lunyu in China}

Translation studies of Lunyu in China started in 1990s, which can be classified into five types according to the study topics: the study of translation version, including the study of one version and the comparative analysis of several versions, the study of translators, the statements in prefaces of their translations, the transmission history of the translation and the study of the key words in the book.

Judging from the study perspective, most of them belong to the linguistic level and scholars mainly focused on the equivalence in translation, some of whom discussed its translation methods on the basis of different theories such as Li Shuang (2004) and Ni Jihua (2007) and some focused on appreciations, such as Yuan Jinxiang (1990), Liu Zhongde (2001), He Gangqiang (2005).

In addition, because of the profound connotations of the key words in Lunyu, which is a difficult point in translation, it becomes one of the research orientations. For example, Wang Hui (2001) put forward the combination of accuracy and unity of translation. Yang Ping (2008b) said that when ren was translated, transliteration should be adopted. 
With the cultural turn in translation, some scholars began to reflect on the extratextual factors. Yang Ping (2008a) and Wang Hui (2007)'s studies well represent the tendency who concentrated on the Christian ideology in missionary translations.

Furthermore, some translation studies took the integrated perspective. Yan Zhenying's book (1971) about Legge's translation is a case in point, which systematically studied Legge's translation and briefly introduced all the other versions. And the integrated perspective can also be found in some articles. For instance, Wang Yong (2007) introduced Edward Slingerland's 2003 version.

From the above, it can be seen that Confucian classic Lunyu attracts numerous scholars at home and abroad and its translation studies have obtained many achievements. However, the study angles are still limited to a certain extent and some key words that carry Confucianism always arouse misunderstandings of target readers and need deeper analysis.

\section{Confucius and Lunyu}

Confucius (511-479BC) is a great philosopher and educator of ancient China who lived in the Spring and Autumn period, which was a transition period from slavery to feudalism. Vassals annexed territories from each other; wars broke out frequently and there was a decline in social morality. To reform society, Confucius established a grand system of thinking, which was mainly contained in Lunyu.

Lunyu is a Confucian classic which appeared in book form in the early years of the Warring States Period. There are 20 chapters, which are broken down into 492 passages. It is a record of the words and deed of Confucius and of his disciples, as well as the discussions they held, expressing Confucius' profound thought.

For thousands of years, Confucianism has exerted a far-reaching influence on Chinese society, culture and psychology. The position of Lunyu in Chinese culture is just like that of the Bible in western culture. Han Wudi rejected other schools of thoughts but held Confucianism in esteem and so its leading position in Chinese history was established. Lunyu was worshipped as a classic in the period of the feudal society and every scholar was required to read it. Its influence was so extensive in China that Lunyu is indispensable even now, either for studies on Confucius himself or for studies in Chinese history. Lunyu is a sound textbook on ethics and politics. Quotations from it are common in China, being used as guidelines for the people's everyday lives, as they are gems of wisdom and philosophical thought.

With China's rapid development of economy, there is a widespread interest in Lunyu and Confucianism around the world. Actually, when it was first introduced to the western world, it was already highly praised by some scholars. R. W. Emerson (1803-1882) and H. D. Thoreau (1817-1862) are two representatives of American transcendentalism. The moment they saw these books they both took a fancy to them and would not let them go. V. Lindsay (1879-1931), a poet, sang heartily to express his ardent love of Confucius: May we be students of the Confucian times. Today, the general impression of Lunyu is higher than any other best sellers; it is only next to the Bible. Alongside the spreading of the classics of the Confucian school headed by Lunyu, Confucianism has already become a hot spot of the humanities in this world.

\section{Translation of Ren and $L i$ in Lunyu}

There are numerous culture-specific items in Lunyu that reflect Confucianism, such as “仁”, “义”, “礼”, “智”, “信”, “忠”, “孝”, “温”, “良”, “恭”, “俭”, “让”, etc. Many of these terms appeared in earlier classics, like The Book of Songs, Yi Ching and Spring and Autumn, but Confucius endowed them with new meanings. However, since Confucius only described but never defined them and since he gave different answers to the same terms depending on his disciples' individual characters and level of understanding, it is very difficult to find their exact definitions. Besides, as classical Chinese is very concise and leads to different interpretations, there are no English equivalents of these terms.

As for the fundamental thought of Lunyu, people have invariably insisted that there are two points of view. One is ren (“仁”). The other is $l i$ (“礼”). Then the paper will discuss the translation of the two main concepts in Lunyu through the comparison of five English versions by foreign and Chinese scholars in different periods of history: The Analects of Confucius by James Legge (hereafter referred as Legge), The Discourses and Sayings of Confucius by Gu Hongming (hereafter referred as Gu), The Analects by Arthur Waley (hereafter referred as Waley), The Analects of Confucius by Pan Fuen and Wen Shaoxia (hereafter referred as Pan \& Wen) and Getting to Know Confucius - A New Translation of The Analects by Lin Wusun (hereafter referred as Lin) and tries to make a comparison between them. 


\subsection{Translation of Ren}

According to the author's statistics, the word “仁” (ren) appears for 109 times in Lunyu. It is the most frequently used word, which reveals its status in the book-ren is central to the Confucian system of thinking. In Chinese, this word means "kind", "gentle", "humane" and in Lunyu it means "good" in an extremely wide and general sense. Different translators understand this word in different ways that is clearly shown in the following table.

Table 1. Translation of ren in the five versions

\begin{tabular}{ll}
\hline Translators & Translations \\
\hline Legge & (perfect) virtue, benevolence \\
Gu & a moral life, a moral man, the true moral character \\
Waley & (the) Good, Goodness \\
Pan \& Wen & perfect virtue, human-heartedness \\
Lin & humaneness, humane \\
\hline
\end{tabular}

From Table 1, we can see that there are different interpretations of the word ren, which is the core of Lunyu. Then what is the true meaning of it? We have to go back to Lunyu. It can be found that Confucius explained ren to his disciples for many times, from which we can see Confucius' understanding of it.

Confucius, in answering his student Fan Chi's question, said ren is to love men and "in private life, courteous; in public life, diligent; in relationships, loyal..." (Waley, 1999) and "to restrain oneself and observe the rituals" (Lin, 2010). And in answering his student Zizhang's question, he also explained that in order to achieve ren one has to practice five things: "gravity, generosity of soul, sincerity, earnestness, and kindness" (Legge, 2009) and "if a man is firm, enduring, simple, and modest, then he is near to virtue" (Ibid.). Fulfilling one's filial and fraternal duties constitute the basics of ren and in order to achieve ren, one should not hesitate to sacrifice his all. Confucius' explanations evidently display that ren does not refer to only one thing. Extensively speaking, it means to apply a policy of benevolence in all lands under heaven. Intensively speaking, it means to love people. It refers to loyalty and consideration, and the fundamental way to be a real human being, namely, filial piety to one's parents and love and respect to one's elder brothers.

Ren is the highest goal and the most ideal state that man may reach. Righteousness, loyalty, forbearance, filial piety, and loving consideration are concrete items under the extensive concept of ren. If one may be able to "extensively confer the benefits on the people," he is more than a "benevolent" person; he may be called a "sage" now. Maybe Yao and Shun were not able to accomplish so much. This tells us that sage contains ren, and ren is in accordance with sage. In Lunyu, Confucius was asked several times to make a comment on other people to say whether they can meet the standard of ren. Confucius gave us the answer. He thought that Zilu, Ran You, Gongxi Hua, Chen Wen and Minister Ziwen, did not achieve the state of ren, and what Yan Yuan reached is only "not contrary to the benevolence" (Waley, 1999). According to Confucius' standard, only the three men (Viscount Wei, Viscount Ji, \& Bi Gan) in Yin dynasty and Guan Zhong can be called "man of virtue". Guan Zhong helped the prince Huan to bring about a stable situation in the whole country for a rather long period so that people might recuperate and multiply, although Confucius thought that Guan Zhong was not parsimonious and did not know the rules of propriety. To be a man of ren in a true sense is very difficult, but everyone can do something to achieve it, that is to say, to do good, it is the practice of keeping the benevolent virtue. It may be accumulated bit by bit in everyday life and the way to carry it out is to put oneself in the place of another, and from the near to the distant.

From the above, it can be seen that actually there is no equivalent of ren in English. Every translator can just try their best to find the approximate meaning of ren on the basis of their own understanding.

James Legge chose the words "(perfect) virtue" and "benevolence". Virtue means moral goodness of character and behavior (Longman Dictionary of Contemporary English, 2004), which is not as extensive as the meaning of ren. Just as what Lin Wusun rendered, it is more proper to be translated into de (“德”) instead of ren. And benevolence means kind and generous, which is little different from the meaning of ren, because Guan Zhong is a man of ren, but he is a man of narrow capacities, according to Confucius.

Gu Hongming preferred the word "moral" that concerns principles of right and wrong behavior, whose meaning is not as extensive as that of ren. It can be said that ren contains morality and has far more connotations than the word "moral".

Waley translated ren into "Good" or "Goodness", capitalizing the first letter. While translating shan (“善”), he 
also used "good". To show the distinction, the latter was not capitalized. Obviously, however, "good" is too general to reflect the connotation of ren, no matter whether it is capitalized or not.

Pan Fuen and Wen Shaoxia used "perfect virtue" and "human-heartedness". They took James Legge, Leonard A. Layall, \& Arthur Waley's versions for reference. And they also found that due to cultural differences, it is hard to find equivalents in English for many important concepts of Confucius. Therefore, they had to retreat for a similar word and adopted the translation method that added Pinyin in brackets when the word first appeared and also made some notes.

Lin Wusun put ren into "humaneness" or "humane" that means treating people or animals in a way that is not cruel and causes them as little suffering as possible (Ibid.), which is inadequate to reflect the essence of ren. Furthermore, in western culture, humaneness is usually connected with the concept of democracy and equality, which is different from the connotation of ren. Thus, it may arouse misunderstandings of western readers. Being aware of the untranslatability of the culture-specific item, Mr. Lin added Pinyin in brackets when they first appeared and also some notes for better understanding, as what Pan and Wen did. Moreover, Chinese characters were supplemented in brackets together with Pinyin to transmit Chinese culture of language.

\subsection{Translation of $\mathrm{Li}$}

The word $l i$ (“礼”) is the second important term that carries Confucius' thought. It appeared in Lunyu for 74 times, which is just next to ren. $L i$ were norms and regulations guiding the behavior of the nobles and relations among them, and the conducting of certain ceremonies, formulated by the founders of the Zhou Dynasty. In Confucius' day, $l i$ was generally ignored, and he wanted to revive it. According to Confucius, ren and $l i$ are inseparable from each other like content and form. Just like ren, it is also a difficult point in translation and different translators have different interpretations.

Table 2. Translation of $l i$ in the five versions

\begin{tabular}{ll}
\hline Translators & Translations \\
\hline Legge & the rules of propriety, what is proper, ceremonies, the rites of propriety \\
Gu & (fine) art(s), courteous, good manners, propriety, civilization, honour, the arts and civilization, judgment, correct \\
& forms, a man of propriety, the principle of the rite, loyalty, courtesy, real courtesy and good manners, etc. \\
Waley & (the) rites, ritual \\
Pan \& Wen & the rules of propriety \\
Lin & rituals, etiquette, rules, regulations \\
\hline
\end{tabular}

$L i$ was rather broad in content. It included rituals, etiquette, regulations and rules of proper behavior. During Confucius' time, there was no official law as we understand it today, but people would be punished when they violated the rules and regulations. Confucius paid great attention to $l i$ which was set down when the Zhou Dynasty was first established. He believed that the neglect of $l i$ was the cause of all troubles of his time. The ministers were neglecting it without any sense of shame, and their stewards and the society at large were following their example. Confucius therefore considered it his mission to advise the powers-to-be to correct their ways through following ren and restoring $l i$. The two concepts are closely related; the former is the root, the latter the branch; the former is the "ins", the latter the "outs"; the former is the content, the latter the form. Ren is the ultimate aim, $l i$ is a kind of binding force and norms and system which guarantees the achievement of the purpose. Ceremony, propriety, system, discipline and law all serve the aim- -all under heaven will converge at benevolence" (Waley, 1999).

From Table 2, it can be seen that most translators chose "rite", "ritual" or "rules of propriety". Rite means a ceremony that is always performed in the same way, usually for religious purposes, and ritual is similar to rite. And propriety means correctness of social or moral behavior (Longman Dictionary of Contemporary English, 2004). They all express one of the connotations of $l i$, which has a wide range of meaning - not only refers to the regulations and norms from the country's perspective but also the social behavior from the individual aspect. Only Gu Hongming used "art" and some other words in different contexts. Gu Hongming's version has evident features, which receives a lot of praise and criticism too. Gu Hongming translated Lunyu because he thought that Legge was just a sinologist who lacked the training of literature and the ability of criticism and the sensation of literature. He severely criticized Legge's version, holding that Legge could not get across the limitation of his stiff and narrow mind so his translation gave readers a strange feeling. Dissatisfied with Legge's translation, Gu Hongming decided to translate it by himself 40 years after the publication of Legge's version. And in order to get rid of the strange feeling of English readers, he removed the Chinese culture-specific items and added some 
notes and quotations from famous European writers to make target readers understand it thoroughly. This is a feature of his translation. The above table clearly reveals his characteristics of translation. He admitted that $l i$ is a word not easily rendered in another language and adopted different words or phrases in different contexts. When li first appeared, he explained it in the notes of more than 300 words, holding the opinion that the word "art" can express the meaning of $l i$. Just because of his obvious characteristics, his translation was studied by many scholars and was also severely criticized by some who think that some of his translations belong to mistranslation. Many scholars believe that his use of "art" may be misleading to target readers.

\section{Conclusion}

Based on the above statement, it seems impossible for us to find an equivalent in English of the culture-specific items in Lunyu, since they all carry profound Chinese traditional culture. In this case, some translators had some nice tries to make them accepted by target readers. For example, Gu Hongming crossed out these culture-specific items and added some notes and quotations from famous European writers that western readers are familiar with. Pan Fuen and Wen Shaoxia also used some notes and when the word first appeared, they added Pinyin to it in brackets. Lin Wusun used Pinyin together with Chinese characters. Actually, with our increasing awareness of transmitting Chinese culture to the world, Pinyin is used more and more frequently than before. There are numerous examples, such as, jiaozi and loong. In the past, people tended to use dumpling and dragon, but now, realizing the cultural differences and the misunderstandings that may be roused, Pinyin is preferred. Additionally, when western readers come across Pinyin, they may realize that it is a culture-specific item and pay special attention to it. And to help target readers understand it, explanatory translation and the notes can be adopted too.

\section{References}

Ames, R. T., \& Rosemont, H. Jr. (1998). The analects of Confucius: A philosophical translation. New York: The Ballantine Publishing Group.

Cheang, A. W. (2000). The master's voice: On reading, translating and interpreting the analects of Confucius. The Review of Politics, 62(3), 563-581.

Durrant, S. W. (1981). On translating Lun Yu. Chinese Literature: Essays, Articles, Reviews (CLEAR), 3(1), 109-119. http://dx.doi.org/10.2307/495339

Girardot, N. J. (2002). The Victorian translation of China. Berkeley and Los Angeles: University of California Press.

He, G. Q. (2005). On the "Twin Legitimacies" in the translating of The Analects-With special reference to Authur Waley's version. Shanghai Journal of Translators, 4, 15-19.

Henderson, J. B., Brooks, E. B., \& Brooks, A. T. (1999). The original analects: sayings of Confucius and his successors; a new translation and commentary by E. Bruce Brooks and A. Taeko Brooks. The Journal of Asian Studies, 58(3), 791-793. http://dx.doi.org/10.2307/2659131

Ku, H. M. (Trans.). (1898). The discourses and sayings of Confucius. Shanghai: Kelly and Walsh, Ltd.

Legge, J. (Trans.). (2009). The analects of Confucius. Beijing: Foreign Languages Press.

Li, S. (2004). A comparative study of the two English versions of Lun Yu by James Legge and Ku Hungming. Chengdu: Sichuan University.

Lin, W. S. (Trans.). (2010). Getting to know Confucius - A new translation of the analects. Beijing: Foreign Languages Press.

Liu, Z. D. (2001). A research into Wale's English version of The Analects and some comments on its English versions by Legge and D. C. Lau. Shandong Foreign Language Teaching Journal, 2, 15-17.

Longman dictionary of contemporary English. (2004). Shanghai: Foreign language Teaching and Research Press.

Ni, J. H. (2007). Equivalence in the English translation of the Analects of Confucius: A socio-semiotic approach. Beijing: China Foreign Affairs University.

Pan, F. E., \& Wen, S. X. (Trans.). (1993). The analects of Confucius. Jinan: Qi Lu Press.

Pfister, L. (1990). Serving or suffocating the sage?-Reviewing the efforts of three nineteenth century translation of the Four Books, with special emphasis on James Legge. The Hong Kong Linguist, (spring \& autumn), $25-55$.

Pfister, L. (2004). Striving for “The Whole Duty of Man”, James Legge and the Scottish Protestant encounter with China. Frankfurt am Main: Peter Lang $\mathrm{GmbH}$. 
Schaberg, D., Ames, R. T., Rosemont, H., Lau, D. C., Dawson, R., Leys, S., \& Brooks, A. T. (2001). "Sell it! Sell it!": Recent translations of Lunyu. Chinese Literature: Essays, Articles, Reviews (CLEAR), 23, 115-139. http://dx.doi.org/10.2307/495503

Slingerland, E. (2000). Review on the original analects by E. Bruce Brooks and A. Taeko Brooks. Philosophy East and West, 50(1), 137-141.

Taam, C. W. (1953). On studies of Confucius. Philosophy East and West, 3(2), 147-165. http://dx.doi.org/10.2307/1397261

Waley, A. (Trans.). (1999). The analects. Changsha: Hunan People's Publishing House \& Beijing: Foreign Languages Press.

Wang, H. (2001). On the translation of key concept words in Confucian Analects. Journal of Shenzhen University (Humanities and Social Sciences), 5, 116-121.

Wang, H. (2007). Christian ideology and three missionary translations of the Lunyu. Journal of Shenzhen University (Humanities and Social Sciences), 6, 122-126.

Wang, Y. (2007). A review of Edward Slingerland's translation on Confucius Analects. Chinese Science and Technology Translators Journal, 1, 59-61. http://dx.doi.org/10.1007/s11430-007-6031-0

Wang, Y. (2010). A comparison of oveseas and domestic studies on English translations of Lun Yu, or Confucius' Analects. Foreign Languages Researches, 2, 70-73.

Yan, Z. Y. (1971). The study on James Legge's translation of The Analects of Confucius. Taipei: Taiwan Commercial Press.

Yang, P. (2008a). Comment on the Christian tendency in missionary translations of Lunyu. Journal of Humanities, 2, 42-47.

Yang, P. (2008b). An analysis of the English translation of the key concept "ren" in Lunyu. Foreign Languages and Their Teaching, 2, 61-63.

Yuan, J. X. (1990). A series of translation studies and appreciations. Wuhan: Hubei Education Press.

\section{Copyrights}

Copyright for this article is retained by the author(s), with first publication rights granted to the journal.

This is an open-access article distributed under the terms and conditions of the Creative Commons Attribution license (http://creativecommons.org/licenses/by/3.0/). 